\title{
INFLUÊNCIA DAS ÉPOCAS DE CONTROLE DAS PLANTAS DANINHAS NA PRODUÇÃO DE LARANJA "PERA" 1
}

\author{
JOSÉ EDUARDO B. de CARVALHO ${ }^{2}$, RANULFO C. CALDAS ${ }^{3}$, SILVANA S. CARDOSO ${ }^{4}$ e \\ ANTÔNIO O. COSTA NETO 5
}

RESUMO

\begin{abstract}
Durante 4 anos agrícolas, conduziu-se um experimento no município de Rio Real, BA, com o objetivo de determinar o período em que as plantas daninhas apresentam maior interferência na produção da cultura durante o ano, levandose em consideração a disponibilidade de água no solo, em função do balanço hídrico climatológico que estimou sua capacidade de armazenamento em $125 \mathrm{~mm}$ de água. Os tratamentos constituíram um arranjo do controle do mato nas quatro épocas pré-estabelecidas. As principais plantas daninhas presentes foram a falsa-serralha (Emilia sonchifolia), capim-colchão (Digitaria horizontalis), capim-favorito (Rynchelitrum roseum) e picão-preto (Bidens pilosa). Na época 1 (dezembro, janeiro e fevereiro) ocorrem pouquís-
\end{abstract}

sima água armazenada no solo e alta deficiência hídrica. A época 2 (março, abril e maio) caracteriza-se por aumento considerável dos índices de armazenamento de água pelo solo, porém sem excedente hídrico e com deficiência em março. A época 3 (junho, julho e agosto) é a única em que ocorre excedente de água armazenada no solo. Setembro, outubro e novembro formam a época 4, quando a disponibilidade de água no solo diminui, aumentando gradativamente a deficiência hídrica. Concluíu-se que para aquele ecossistema o pomar deve ser mantido livre da interferência da comunidade infestante a partir de setembro/outubro até abril/maio.

Palavras-chave: período crítico, competição, citros, Citrus sinensis.

\section{ABSTRACT \\ Influence of weed control timing on the production of orange}

Over a period of 4 years a trial was carried out to determine the time when interference of weeds with plant production was highest. Water availability was considered to be $125 \mathrm{~mm}$ based on climatic water balance to estimate the soil's water storability. The main weeds were Emilia sonchifolia, Digitaria horizontalis, Rynchelitrum roseum and Bidens pilosa. In period 1 (December to February) very little water is stored in the soil and there is a water deficit. In period 2 (March to May) a marked increase in water storage is observed; however with no plant availability and with a storage in March. Only in period 3 (June to August) occurrs a surplus of storage water. During period 4 (September to November) water availability in the soil decreases and the water deficit increases progressively. It is concluded that in this ecosystem orchards must be kept free of weeds from September/October to April/May.

Additional index words: Critical period, competition, citrus, Citrus sinensis.

1 Recebido para publicação em 30/08/93 e na forma revisada em 03/03/94.

2 Eng $^{\circ}$.- Agr ${ }^{\circ}$., PhD., Pesquisador da EMBRAPA-Centro Nacional de Pesquisa de Mandioca e Fruticultura Tropical, Caixa Postal 007, CEP 44.380-000 Cruz das Almas, BA.

3 Eng ${ }^{\circ}$-Agr ., MSc., Pesquisador da EMBRAPA-Centro Naciona1 de Pesquisa de Mandioca e Fruticultura Tropical, Caixa Posta1 007, CEP 44.380-000 Cruz das Almas, BA.

4 Eng $^{\circ}$.- Agr $^{\circ}$, Bolsista do CNPq., CEP 44380-000 Cruz das Almas, BA.

5 Graduando em Engenharia Agronômica pela Universidade Federa1 da Bahia - Cruz das Almas, BA - Bolsista do CNPq. CEP 44380-000 Cruz das Almas, BA. 


\section{INTRODUÇÃO}

No Nordeste brasileiro há grande carência de informações básicas e fundamentais sobre o manejo do mato, que possibilite seu controle racional e econômico, evitando a competição das plantas daninhas pelos fatores de produção com a cultura dos citros. E de suma importância a identificação desses fatores, principalmente nos solos de tabuleiros costeiros, caracterizados como de baixa fertilidade e reduzida capacidade de retenção de água. Nesses solos a produtividade média não ultrapassa 13 t/ha, considerada baixa, pois é inferior ao rendimento médio do país, que se encontra em torno de $20 \mathrm{t} / \mathrm{ha}$, e muito inferior ao de outros países como os EUA, Itália e Espanha, que produzem entre 30 e 40 t/ha. O controle das plantas daninhas, quando efetuado correta e oportunamente, contribui para aumentar a produtividade dos citros sem elevar os custos de produção.

Existem alguns trabalhos relatando as principais plantas daninhas que ocorrem nos pomares, como o de Rodriguez (1969), que coloca a família Gramíneae como a mais importante, seguida das familías Compositae, Malvaceae e Euphorbiaceae. Estas competem coma cultura por água, luz, nutrientes e $\mathrm{CO}_{2}$. $\mathrm{O}$ grau desta competição está em função do tipo, da densidade da comunidade infestante e da época do ano em que permanecem juntas, vegetando.

Quanto mais competitiva a vegetação, mais adversamente ela altera a fisiologia da planta, seu crescimento, produção e qualidade (Jordan, 1992).

A exigência dos citros por água situa-se entre 1900$2400 \mathrm{~mm}$, com um mínimo em torno de $1300 \mathrm{~mm}$ de precipitação, cuja falta ou distribuição inadequada pode limitar a produção, a qual geralmente é máxima em áreas irrigadas (Malavolta \& Violante Netto, 1989). Nessas áreas, a planta cítrica alcança maior crescimento vegetativo de ramos, aumentando a sua capacidade de produção (Goell, 1992).

Em função do tipo de solo de tabuleiros costeiros, predominante na região citrícola do Recôncavo baiano, Cintra \& Coelho (1987) afirmaram que é indispensável a adoção de práticas culturais que permitam aumentar os teores de matéria orgânica e a capacidade de retenção de água desse solo para se obter melhores produtividades. Nesta mesma linha de raciocínio, Oliveira (1986) concluiu que as condições físicas do solo favoráveis ao crescimento e capacidade de absorção de água pelas raízes parecem ser mais importantes do que a fertilidade natural para a produção dos citros. A localização muito superficial das radicelas da laranjeira indica, segundo Moreira (1992), a necessidade de se considerar com muito cuidado o manejo do solo no pomar.

Rodriguez (1957) concluíu que no planalto paulista ocorre um período de relativa falta de chuvas no inverno, ocasionando reduções dos teores de água do solo, sendo, portanto, necessário controlar o mato nessa época. Segundo esse mesmo autor, a prática de manejo normalmente usada consiste em manter o pomar cítrico livre do mato na época seca e deixar alguma vegetação intercalar no período das chuvas para reter água, evitando a erosão. Todavia, próximo às plantas, o controle do mato deve ser feito durante todo o ano. Campos (1976) e Caetano (1980) também indicaram as mesmas épocas para controle do mato nos pomares do Estado de São Paulo.
Em um experimento realizado no município de Limeira, onde se compararam os tratamentos solo vegetado com as plantas daninhas ceifadas duas vezes ao ano, de setembro a abril; solo com adubo verde plantado em outubro e destruído em abril e mato ceifado nas águas e limpo nas secas, Rodriquez (1969) concluiu que as maiores produções foram obtidas com a adubação verde, superando em 29 e $36 \%$ o tratamento mato ceifado, quando se usou o feijão guandu e soja perene, respectivamente. O tratamento limpo na seca e com mato ceifado nas águas apresentou produção intermediária.

Na Africa do Sul, a ausência de cultivo ou o cultivo mínimo em citros tem aumentado, devido, principalmente, aos danos provocados pelo cultivo mecânico às raízes e ramos das plantas. A cobertura com gramíneas, embora tenha aumentado o teor de matéria orgânica do solo, reduziu a produção cítrica devido à competição por água e nutrientes (Herboldt, 1969).

$\mathrm{O}$ efeito de diversos tratos culturais sobre o crescimento, produção, qualidade do fruto e teores de nutrientes da folha de laranja 'Valência', foi estudado por Economides (1976) que, após dez anos, não encontrou influência dos tratamentos sobre os teores de diversos nutrientes. Em um estudo no Rio Grande do Sul sobre o efeito de sistemas de manejo do solo sobre o desenvolvimento vegetativo e qualidade de frutos das laranjas 'Valência' e 'Baianinha', e sobre a fertilidade do solo, Koller et al. (1977) observaram que a manutenção da vegetação nativa ceifada diminuiu o desenvolvimento e a produção das duas variedades e que a percentagem de suco, a acidez e o teor de sólidos solúveis dos frutos não foram afetados pelos sistemas de manejo.

A ceifa permanente das plantas daninhas permitiu a manuntenção das características físicas do solo e melhoria na sua estrutura, graças ao incremento do teor de matéria orgânica. A gradagem permanente promoveu a redução do tamanho dos agregados e da percentagem de agregação, além de formar uma camada compactada numa profundidade de 10 a $15 \mathrm{~cm}$. O uso de herbicidas promoveu a formação de crostas superficiais, alterando as propriedades físicas do solo e reduzindo a velocidade de infiltração $d a$ água (Cintra et al., 1983).

Em um experimento conduzido em Limeira, SP, para verificar a época em que o mato provoca prejuízos à produção dos citros, Blanco \& Oliveira (1978) concluíram que o mato deve ser controlado de dezembro a março ou de agosto a novembro.

Jordan (1992) concluiu que os resultados da com petição das plantas invasoras com os citros são usualmente negativos e resultam em menor produção e pior qualidade do fruto.

Esse trabalho teve por objetivo determinar as épocas do ano em que as plantas invasoras apresentam maior grau de competição com a cultura dos citros, levando-se em consideração a disponibilidade de água no solo.

\section{MATERIAL E MÉTODOS}

O experimento foi conduzido, a partir de março de 1989, em Rio Real, ecossistema representativo para a cultura 
dos citros no Estado da Bahia, na agroindústria Citrocultura do Nordeste Ltda. O manejo da cultura, exceto as limpas, obedeceu ao sistema de produção utilizado pela Empresa e recomendado pelo Centro Nacional de Pesquisa de Mandioca e Fruticultura Tropical.

$\mathrm{O}$ delineamento experimental foi em blocos casualizados com dez tratamentos e cinco repetições. A variável rendimento de frutos em tonelada por hectare foi submetida à análise de variância dentro de cada ano agrícola e os tratamentos comparados pelo Teste de Tukey a 5\%. Para se estudar o efeito do ano agrícola, foi efetuada a análise conjunta desta variável. Os tratamentos constituíram-se em realizar o controle das plantas daninhas em épocas pré-estabelecidas durante o ano (Tabela 1). As parcelas foram formadas por quatro plantas, sendo duas úteis, das quais foram computados os rendimentos e avaliados a percentagem de suco, a acidez total e os graus brix.

A variedade selecionada para o trabalho foi a 'Pera' (Citrus sinensis (L) Osbeck) plantada no espaçamento de $6 \mathrm{~m}$ x $4 \mathrm{~m}$, com aproximadamente 4 anos de idade, enxertada em porta-enxerto de limão 'Cravo' (Citrus limonia, Osbeck).

O controle do mato foi realizado através de enxada, de forma manual, nas épocas estabelecidas, tomando-se como critério para realização das límpas toda vez que a cobertura da parcela pelas plantas daninhas atingia uma infestação visual média de $15 \%$. Antes da implantação do experimento todas as parcelas foram capinadas, dando-se condição de igualdade de infestação para todos os tratamentos.

Considerou-se como rendimento em t/ha a somatória das colheitas realizadas durante o ano agrícola.

Na Tabela 2 está o balanço hídrico-climatológico de Cruz das Almas, elaborado por Carmo (1973), determinado pelo método de Thorntwait \& Mater, e utilizado para definição das épocas de limpas, em virtude da semelhança edafoclimática dos dois locais e por não se dispor desses dados do município de Rio Real. A capacidade de armazenamento de água pelo solo foi estimada em $125 \mathrm{~mm}$. Descrição das épocas agrupadas na Tabela 2:

EPOCA 1: Ocorrem pouquíssima água armazenada no solo e alta deficiência hídrica;

ÉPOCA 2: Caracteriza-se por aumento considerável dos índices de armazenamento de água pelo solo, porém, sem excedente hídrico e com deficiência em março;

ÉPOCA 3: É a única época em que ocorre excedente hídrico; EPOCA 4: A água armazenada no solo diminui, aumentando o deficiência hídrica.
As principais plantas daninhas presentes no experimento foram falsa-serralha (Emilia sonchifolia (Vahl)DC), capim-colchão (Digitaria horizontalis Will), capim-favorito (Rhynchelitrum roseum (Ness) Stapf. et Hubb), picão-preto (Bidens pilosa L.), carrapicho-de-carneiro (Acanthospermum hispidum DC), beldroega (Portulaca oleracea L.), trapoeraba (Commelina benghalensis L.) e cama-de-coelho (Eupatorium ballataefolium HBK).

$\mathrm{Na}$ Figura 1, é mostrada a distribuíção mensal das precipitações pluviais ocorridas no ecossitema em estudo nos anos agrícolas 1988/93.

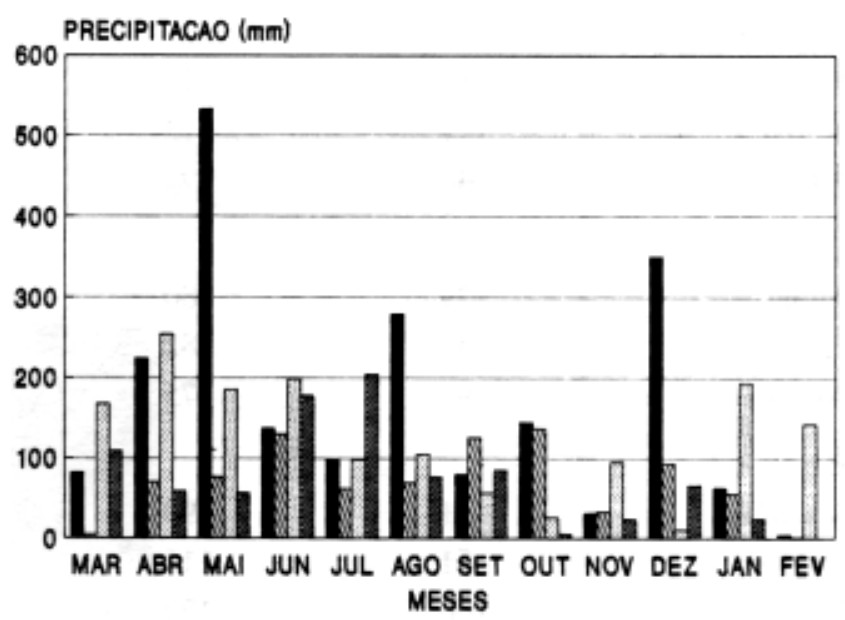

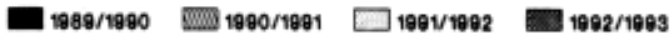

FIG. 1 - Precipitação pluvial ocorrida em Rio Real nos anos agrícolas 1989/1993.

\section{RESULTADOS E DISCUSSÃO}

São apresentados na Tabela 3 as produções médias dos quatro anos agrícolas e os resultados das análises estatísticas individuais e conjuntas.

No ano agrícola 1988/89, apenas o tratamento 7 diferiu significativamente dos tratamentos 8 e 10 . Os demais não diferiram estatisticamente entre si. Apesar dessa equivalência, dois dos tratamentos testados (T4 e T7) tiveram os mais altos rendimentos em t/ha de frutos, com incrementos de produção de $8 \%$ e $38 \%$, respectivamente, em relação ao tratamento 5 que apresentou o terceiro melhor rendimento.

TABELA 1 - Arranjo dos tratamentos estudados em Rio Real no período de março de 1989 a março de 1993, em função das épocas do ano estabelecidas a partir do balanço hídrico-climatológico.

\begin{tabular}{l|c|c|c|c|c|c|c|c|c|c}
\hline \multirow{2}{*}{$\begin{array}{c}\text { Épocas de controle } \\
\text { do mato }\end{array}$} & \multicolumn{10}{c}{ Tratamentos } \\
\cline { 2 - 12 } & $\mathbf{1}$ & $\mathbf{2}$ & $\mathbf{3}$ & $\mathbf{4}$ & $\mathbf{5}$ & $\mathbf{6}$ & $\mathbf{7}$ & $\mathbf{8}$ & $\mathbf{9}$ & $\mathbf{1 0}$ \\
\hline 1 (Dez.,Jan.,fev.) & $\mathrm{L}$ & $\mathrm{M}$ & $\mathrm{L}$ & $\mathrm{L}$ & $\mathrm{M}$ & $\mathrm{M}$ & $\mathrm{L}$ & $\mathrm{L}$ & $\mathrm{M}$ & $\mathrm{M}$ \\
2 (Mar.,Abr.,Mai.) & $\mathrm{L}$ & $\mathrm{L}$ & $\mathrm{M}$ & $\mathrm{L}$ & $\mathrm{M}$ & $\mathrm{L}$ & $\mathrm{L}$ & $\mathrm{M}$ & $\mathrm{M}$ & $\mathrm{M}$ \\
3 (Jun.,Jul.,Ago.) & $\mathrm{L}$ & $\mathrm{M}$ & $\mathrm{M}$ & $\mathrm{L}$ & $\mathrm{M}$ & $\mathrm{L}$ & $\mathrm{M}$ & $\mathrm{L}$ & $\mathrm{L}$ & $\mathrm{M}$ \\
4 (Set.,Out.,Nov.) & $\mathrm{L}$ & $\mathrm{L}$ & $\mathrm{L}$ & $\mathrm{M}$ & $\mathrm{L}$ & $\mathrm{M}$ & $\mathrm{M}$ & $\mathrm{M}$ & $\mathrm{L}$ & $\mathrm{M}$ \\
\hline
\end{tabular}

$\mathrm{L}=$ Limpo $\quad \mathrm{M}=\mathrm{Mato}$

Planta Daninha, v. 11, n. 1/2, 1993. 
TABELA 2 - Balanço hídrico-climatológico do município de Cruz das Almas - Bahia pelo método de Thorntwait \& Mater, 1955.

\begin{tabular}{|c|c|c|c|c|c|}
\hline Épocas do ano & $\begin{array}{c}\text { Precipitaçáo (P) } \\
(\mathrm{mm})\end{array}$ & $\begin{array}{l}(\mathbf{E P})^{*} \\
(\mathbf{m m})\end{array}$ & $\begin{array}{c}\text { Armazenamento } \\
(\mathbf{m m})\end{array}$ & $\begin{array}{l}\text { Déficit hídrico } \\
(\mathbf{m m})\end{array}$ & $\begin{array}{c}\text { Excedente hídrico } \\
(\mathbf{m m})\end{array}$ \\
\hline \multicolumn{6}{|l|}{ ÉPOCA 1: } \\
\hline Dezembro & 88 & 139 & 31 & 35 & 0 \\
\hline Janeiro & 66 & 145 & 16 & 64 & 0 \\
\hline Fevereiro & 71 & 135 & 10 & 58 & 0 \\
\hline \multicolumn{6}{|l|}{ ÉPOCA 2: } \\
\hline Março & 112 & 135 & 8 & 21 & 0 \\
\hline Abril & 151 & 112 & 47 & 0 & 0 \\
\hline Maio & 148 & 95 & 100 & 0 & 0 \\
\hline \multicolumn{6}{|l|}{ ÉPOCA 3: } \\
\hline Junho & 129 & 80 & 125 & 0 & 24 \\
\hline Julho & 131 & 82 & 125 & 0 & 49 \\
\hline Agosto & 92 & 75 & 125 & 0 & 17 \\
\hline \multicolumn{6}{|l|}{ ÉPOCA 4: } \\
\hline Setembro & 51 & 90 & 90 & 4 & 0 \\
\hline Outubro & 51 & 116 & 53 & 38 & 0 \\
\hline Novembro & 106 & 124 & 46 & 11 & 0 \\
\hline
\end{tabular}

- $\mathrm{EP}=$ Evapotranspiração potencial.

No segundo ano de execução do trabalho (1990/91), a tendência foi a mesma do ano anterior. Observa-se pela Tabela 3 que a maior produção de frutos em t/ha foi do tratamento 7, seguido pelos $1,4,6,2$ e 9 que, porém, só diferiram estatísticamente do tratamento 10.

Nos anos agrícolas 1991/92 e 1992/93 os tratamentos não diferiram entre si pelo teste de Tukey ao nível de 5\% de probabilidade. Apesar dessa igualdade estatística, alguns tratamentos apresentaram rendimentos superiores aos demais, tendência essa já observada nos dois primeiros anos. Assim, no quarto ano, as maiores produções foram alcançadas em ordem decrescente pelos tratamentos 1,7,4 e 2, com incrementos de $34 \%, 32 \%, 22 \%$ e $15 \%$, respectivamente, em relação ao tratamento 3 , cujo rendimento em t/ha de frutos foi imediatamente inferior ao destes.

$\mathrm{Na}$ análise conjunta de variância, detectou-se efeito significativo do fator ano, como também da interação ano $\mathrm{x}$ tratamentos, porém, esta significação foi causada exclusivamente pelo ano agrícola 1991/92. Quando se eliminou este ano agrícola da análise, os tratamentos continuaram apresentando significação estatística. $\mathrm{O}$ mesmo não ocorreu com o efeito de ano e com a interação ano x tratamento. Nota-se na Tabela 3 que naquele ano houve queda acentuada do rendimento de frutos $(\mathrm{t} / \mathrm{ha})$, independente do tratamento testado. Fato atribuído ao efeito da alternância na produção de laranja 'Pera'. Verificou-se também pela mesma análise que o tratamento 7 foi o que apresentou a mais alta produção de frutos (t/ha) sem, contudo, diferir significativamente pelo teste de Tukey a 5\% dos tratamentos 1, 4 e 2, mas diferindo dos demais. As perdas de produção provocadas pela compe- tição das plantas daninhas foram da ordem de $43 \%$ entre tratamento sempre no limpo e sempre no mato. Resultado semelhante (41\%) foi obtido por Blanco \& Oliveira (1978).

O balanço hídrico climatológico utilizado no trabalho para a definição das épocas de limpas caracterizou uma estação seca que extende-se de setembro a março (Tabela 2). Assim, nos meses considerados secos, as precipitações pluviais são insuficientes para suprir a deficiência hídrica, uma vez que na sua maioria são inferiores a $100 \mathrm{~mm}$ mensais, como ocorreu na área experimental (Figura 1), caracterizando uma distribuição inadequada para que a cultura expressasse seu potencial produtivo, segundo Malavolta \& Violante Netto (1989).

Os resultados estão coerentes com o balanço hídrico climatológico, tomando como referência, e com as precipitações pluviais ocorridas na área experimental, levando-se a admitir que, dentre os fatores de produção, a competição das plantas daninhas por água, reduzindo o suprimento hídrico no solo, foi a mais significativa para a queda do rendimento da laranja 'Pera' naquele ecossistema. Os tratamentos, onde as limpas foram realizadas nos meses de dezembro a maio e por todo o ano agrícola, apresentaram os mais altos rendimentos em t/ha de frutos (em ordem decrescente, 17, T1 e T4), seguidos pelo tratamento 2 , onde uma das épocas de limpas compreendeu os meses de setembro, outubro e novembro (Tabela 3). Os resultados desse trabalho corroboram as afirmativas de Malavolta \& Violante Netto (1989), Oliveira (1986), Cintra \& Coelho (1987), quando admitem que a disponibilidade de água no solo e práticas culturais, que permitam mantê-la por uni período mais longo possível 
TABELA 3 - Efeito dos tratamentos sobre o rendimento de laranja 'Pera' em t/ha de frutos nos quatro anos agrícolas no ecossistema de Rio Real, BA.

\begin{tabular}{|c|c|c|c|c|c|}
\hline \multirow{2}{*}{$\begin{array}{c}\text { Tratamentos/Épocas do ano } \\
{[\text { [E1,E2,E3,E4] }}\end{array}$} & \multicolumn{4}{|c|}{ Ano agrícola } & \multirow{2}{*}{ Média } \\
\hline & $1989 / 90$ & 1990/91 & $1991 / 92$ & $1992 / 93$ & \\
\hline 1. $\mathrm{L}+\mathrm{L}+\mathrm{L}+\mathrm{L}$ & $33,54 \mathrm{ab}^{1}$ & $42,60 \mathrm{a}$ & $13,42 \mathrm{a}$ & 45,05 a & $33,65 a b$ \\
\hline 2. $\mathrm{M}+\mathrm{L}+\mathrm{L}+\mathrm{L}$ & $32,22 \mathrm{ab}$ & 38,33 a & 10,25 a & 38,44 a & $29,81 \mathrm{abc}$ \\
\hline 3. $\mathrm{L}+\mathrm{M}+\mathrm{M}+\mathrm{L}$ & $34,26 a b$ & $25,41 \mathrm{ab}$ & 13,04 a & 33,51 a & 26,55 bcd \\
\hline 4. $\mathrm{L}+\mathrm{L}+\mathrm{L}+\mathrm{M}$ & $39,70 \mathrm{ab}$ & 38,94 a & 14,83 a & 41,05 a & $33,63 \mathrm{ab}$ \\
\hline 5. $\mathrm{M}+\mathrm{M}+\mathrm{M}+\mathrm{L}$ & $36,68 \mathrm{ab}$ & $25,95 \mathrm{ab}$ & $10,18 \mathrm{a}$ & 31,21 a & $26,01 \mathrm{bcd}$ \\
\hline 6. $\mathrm{M}+\mathrm{L}+\mathrm{L}+\mathrm{M}$ & $35,30 \mathrm{ab}$ & 38,94 a & 10,86 a & $30,30 \mathrm{a}$ & $28,85 \mathrm{bc}$ \\
\hline 7. $\mathrm{L}+\mathrm{L}+\mathrm{M}+\mathrm{M}$ & 50,54 a & 43,14 a & 14,02 a & 44,25 a & 37,99 a \\
\hline 8. $\mathrm{L}+\mathrm{M}+\mathrm{L}+\mathrm{M}$ & $25,58 \mathrm{~b}$ & $25,39 \mathrm{ab}$ & $11,08 \mathrm{a}$ & 27,18 a & $22,31 \mathrm{~cd}$ \\
\hline 9. $\mathrm{M}+\mathrm{M}+\mathrm{L}+\mathrm{L}$ & $32,56 \mathrm{ab}$ & 31,84 a & 13,82 a & 24,34 a & $25,64 \mathrm{bcd}$ \\
\hline 10. $\mathrm{M}+\mathrm{M}+\mathrm{M}+\mathrm{M}$ & $27,44 \mathrm{~b}$ & $10,17 \mathrm{~b}$ & 7,12 a & 32,02 a & $19,19 \mathrm{~d}$ \\
\hline Teste F & $*$ & $* *$ & n. s. & n. s. & $* *$ \\
\hline Média (x) & 34,78 & 32,07 & 11,86 & 34,73 & 28,36 \\
\hline C.V. (\%) & 29,60 & 26,10 & 32,00 & 32,10 & 31,30 \\
\hline
\end{tabular}

\footnotetext{
$\mathrm{L}=$ Limpo $\mathrm{M}=\mathrm{M}$ ato

•p $\leq 0.5 ; \cdots p \leq 0,01 ;$ n. s. não significvativo

1 Valores com letras iguais dentro da mesma coluna, năo diferem estastiticamente pelo teste de Tukey a $5 \%$.

E1 = Dezembro, janeiro, fevereiro

$\mathrm{E} 2$ = Março, abril, maio

$\mathrm{E} 3$ = Junho, julho, agosto

$\mathrm{E} 4$ = Setembro, outubro, novembro
}

durante o ano, são mais importantes que a fertilidade natural do solo para a produção de citros. A competição por água também foi relatada por Herbolot (1969).

No Estado de São Paulo, Blanco \& Oliveira (1978) concluíram que o mato provocou queda na produção quando esteve presente no período chuvoso. Neste caso, admite-se que a principal causa da discrepância entre os dois resultados seja a maior capacidade de retenção de água daquele solo, atendendo melhor às necessidades da cultura nas épocas de menores índices pluviais, fato que não ocorre em Rio Real, onde o solo, é caracterizado como latossolo colônia, terciário da série Barreiras, sedimento areno-argiloso com baixíssima capacidade de retenção de água. Um outro fator, que pode ter contribuído para proporcionar essa alta competição das plantas daninhas por água, é que o solo apresenta uma camada adensada logo abaixo do horizonte $\mathrm{A}$, de aproximadamente 1 $\mathrm{m}$ de espessura, impedindo nas épocas de deficiência hídrica a penetração das raízes das plantas cítricas, reduzindo assim o volume de exploração.

Os resultados obtidos em Rio Real discordam também daqueles obtidos por Rodriguez (1957), Campos (1976) e Caetano (1980), os quais recomendam o controle do mato na projeção da copa durante todo o ano.

Para as condições edafoclimáticas da área experimental, ficou demonstrado que a convivência das plantas daninhas com a laranja Pera' no período de deficiência hídrica no solo, a partir de setembro e extendendo-se até março, foi a principal responsável pelas perdas de produção. Este fato sugere que a cultura deve ficar livre dessa convivência de setembro/outubro até abril/maio, pois, segundo Carmo (1973), as precipitações ocorridas em abril e maio, apesar de serem superiores à evapotranspiração potencial, não são suficientes para saturar o solo (Tabela 2).

Não se observou influência dos tratamentos sobre a percentagem de suco, acidez total e grau brix, pois comportaram-se estatisticamente semelhantes pelo teste de Tukey a $5 \%$ de probabilidade.

Os resultados obtidos permitem concluir que:

1. Na região de Rio Real a cultura deve permanecer livre de plantas daninhas a partir de setembro/outubro até abril/ maio;

2. Elevou-se a produtividade de citros pelo manejo racional e oportuno da comunidade infestante, sem elevação dos custos de produção;

\section{LITERATURA CITADA}

BLANCO, H.G. \& OLIVEIRA, D.A. Estudos dos efeitos da época de controle do mato sobre a produção de citros e a composição da flora daninha. Arquivo Instituto Biológi co, São Paulo, v. 45, n. 1, p. 25 - 36, 1978.

CAETANO, A.A. Tratos culturais. In: RODRIGUEZ, O. \& VEIGAS, F.C.P., ed. Citricultura Brasileira, São Paulo: Fundação Cargill, 1980. p. 431-444.

CAMPOS, J.S. Cultura dos Citros. Campinas,SP: Coordenadoria de Assistência Técnica Integral, 1976. 100p. 
CARMO, G.F.do. Balanço hídrico do município de Cruz das Almas segundo Thorntwaite \& Mather, 1955. In: BAHIA. Universidade Federal. Escola de Agronomia. Projeto de Mandioca. Cruz das Almas, BA, 1973. p.61-77 (Série Pesquisa, ano 1, n.1).

CINTRA, F.L.D.; COELHO, Y.da S.; CUNHA SOBRINHO, A.P. da \& PASSOS, O.S. Caracterização Mica do solo submetida a práticas de manejo em pomar de laranja 'Baianinha'. Pesquisa Agropecuária Brasileira, Brasília, v. v. 18, n. 2, p. 173-79, 1983.

CINTRA, F.L.D. \& COELHO, Y. da S. Caracterização física do solo em pomares da região citrícola do Recôncavo Baiano. Revista Brasileira de Fruticultura, Cruz das Almas, v. 9, n.1, p. 27-35, 1987.

ECONOMIDES, C.V. Effects of certain cultural practices on tree growth, yield and fruit quality of 'Valencia' orange in Cyperus rotundus. Journal of Horticultural Science, v. 51, p. 545-549, 1976.

GOELL, A. Fisiliologia da Irrigação. In: Seminário Internacional de Citros, 2, 1992, Bebedouro. Anais... Campinas, SP: Fundação Cargil, 1992. p.173-176.

HERBOLDT, J.A. Weed control in South African citrus orchards. In: International Citrus Symposium, 1, 1967. Riverside, Califórnia, 1969. Proceedings... Riverside, Califórnia: 1969. p.499-502.
JORDAN, L.S. Efeito das plantas daninhas e seu controle nas plantas cítricas. In: Seminário Internacional de Citros, 2, 1992, Bebedouro. Anais... Campinas, SP: Fundação Cargil, 1992. p.163-171.

KOLLER, O.C.; BARRADAS, C.I.N. \& PEREIRA, A. Efeito de dois sistemas de manejo do solo sobre a produção de duas variedades de laranjeira doce Citrus sinensis (L.) Osbeck. In: Congresso Brasileiro de Fruticultura, 4, 1977, Salvador, BA. Anais... Salvador, BA: SBF, 1977. p. 183-190.

MALAVOLTA, E. \& VIOLANTE NETTO, A. Nutrição mineral, calagem, gessagem e adubação dos citros. Piracicaba, S.P.: Associação Brasileira para a Pesquisa da Potassa e do Fosfato, 1989. 153p.

MOREIRA, C.S. O sistema radicular das plantas cítricas. In: Seminário Internacional de Citros, 2, 1992, Bebedouro. Anais... Campinas: Fundação Cargil, 1992. p.182-185.

OLIVEIRA, J.B. Solos para a citricultura no Estado de São Paulo. Laranja, Cordeirópolis, v.7, n. 1, p. 337-351, 1986.

RODRIGUEZ, O. Manejo de solo em pomar cítrico. O Agronômico, Campinas, v.9, p. 17-22, 1957.

RODRIGUEZ, O. Problemas de ervas daninhas em pomares cítricos no Estado de São Paulo. In: Congresso Nacional de Botânica, 20, 1969, Goiânia. Anais... Goiânia: 1969. p. 19-23. 